\title{
0 filósofo e o psicanalista: linguagens e corpos em Deleuze e Lacan
}

\author{
The philosopher and the psychoanalyst: languages and bodies in Deleuze and Lacan
}

Pedro Sobrino Laureano

Mestre em Teoria Psicanalítica pela Pontifícia Universidade Católica do Rio de Janeiro (PUCRio), Rio de Janeiro, RJ - Brasil, e-mail:

edro@laureanopsi.com.br

Recebido: 11/01/2012 Received: 01/11/2012

Aprovado: $15 / 11 / 2012$ Approved: 11/15/2012

\section{Resumo}

O objetivo deste trabalho é propor uma reflexão crítica sobre a relação entre o pensamento de Gilles Deleuze e o de Jacques Lacan. Buscamos abordar, principalmente, uma transformação ocorrida na leitura feita por Deleuze da obra de Lacan: este, de aliado do projeto filosófico do autor, passa a ser alvo de crítica. Para desenvolver tal questão, utilizamos principalmente a concepção de linguagem presente em ambos os autores. Partindo, na primeira parte de nosso trabalho, da lógica do sentido deleuziana, buscamos explicitar a presença do pensamento de Lacan dentro do projeto filosófico de Deleuze. Na segunda parte de nosso trabalho, apresentamos as teses de Lacan, buscando mostrar porque foi necessário a Deleuze desvencilhar-se da concepção lacaniana de linguagem, e, portanto, de sujeito. Nossa questão nos levou, então, a investigar a necessidade, na filosofia de Deleuze (e em sua obra escrita em colaboração com Félix Guattari), de se pensar um Corpo sem Órgãos (CsO), ou plano de imanência, irredutível ao conceito lacaniano de real.

Palavras-chave: Linguagem. Diferença. Inconsciente. Significante. Corpo sem Órgãos.

\section{Abstract}

Our work's aim is to propose a critical reflection on the relationship between the thinking of Gilles Deleuze and Jacques Lacan. We search to analyze, mainly, a transformation occurred in Deleuze's reading of the work of Lacan: once an ally of Deleuze's philosophical project, Lacan's thinking became a target of Deleuze criticism. To develop this question, we have used, mainly, the conception of language present in both authors. Starting, in the first part of our work, from Deleuze's logic of sense, we search to explicit the presence of Lacan's ideas in Deleuze's philosophical project. In the second part of our work we present Lacan's thesis in order to explain why it was necessary to Deleuze to get rid of Lacan's conception of language and, consequently, of the subject. Our problem has led us, then, to investigate the necessity, for Deleuze's philosophy (and his work written in collaboration with Félix Guattari) of thinking a Body without Organs, or plane of immanence, irreducible to the Lacanian concept of real.

Keywords: Language. Difference. Unconscious. Signifier. Body without Organs. 


\section{Introdução}

Propomos, neste artigo, explorar as divergências e aproximações entre dois pensamentos distintos, o de Gilles Deleuze e o de Jacques Lacan. Procuraremos desenvolver as ressonâncias complexas que podem ser tecidas entre as duas obras a partir de uma reflexão sobre a teoria da linguagem e do sentido presente no pensamento dos autores. Esperamos poder mostrar como há afinidade possível entre ambos, no sentido de que tanto Deleuze como Lacan buscam construir pensamentos críticos ao paradigma representacional da filosofia clássica. Mas também esperamos indicar os limites desta afinidade, mostrando como, para Deleuze, o recurso à estrutura simbólica e à lógica do significante é a partir do $O$ anti-Édipo (2010) radicalmente excluído, passando a constituir objeto de crítica radical.

Para desenvolver nosso objetivo, analisaremos primeiramente a concepção deleuziana de linguagem presente em A lógica do sentido (2007), testemunha de uma época em que o filósofo era tributário de certos aspectos da teoria de Lacan. Em seguida, passaremos a explicitar a concepção lacaniana do inconsciente linguístico, para, finalmente, na parte final de nosso artigo, delimitarmos algumas das afinidades e diferenças entre os projetos dos autores. Esperamos esclarecer desta maneira porque Deleuze, a partir de sua primeira obra escrita com Félix Guattari, $O$ anti-Édipo, torna-se crítico de alguns dos postulados fundamentais da psicanálise lacaniana, e porque tal postura foi necessária à construção de sua filosofia, na elaboração do conceito de Corpo sem Órgãos ( $\mathrm{CsO}$ ), ou plano de consistência.

\section{Deleuze e a lógica do sentido}

Em A lógica do sentido Deleuze busca construir uma teoria pós-representativa da linguagem, tendo como um de seus principais aliados, para tal empreendimento, a lógica estoica do acontecimento imaterial. 0 problema é concebido como sendo o da conquista de uma superfície de sentido para além da dicotomia entre a profundidade material do não senso (ação e paixão dos corpos) e as alturas dos sentidos últimos e significados perenes (ideias primeiras).

Segundo Deleuze, a lógica estoica do acontecimento incorporal afirma que o expresso das proposições é um efeito da ação e paixão dos corpos, mas que a relação entre causa e efeito não é transcendente. 0 "incorporal", como acontecimento, não designa uma forma para além dos corpos, como o eîdos na doutrina das ideias platônicas ${ }^{1}$, mas um expresso, um extrasser cuja insistência, como efeito, não produz um espelhamento do mundo empírico. Pelo contrário, a linguagem torna-se aqui capaz de exprimir o ser como acontecimento, e não representação. Trata-se de um "salto no próprio lugar" (Deleuze, 2007, p.152) no qual o que era, na ação e paixão entre os corpos, um presente puro e homogêneo, encadeado segundo séries de causalidade linear, adquire sentido como acontecimento que exprime a diferença interna, elemento responsável pela gênese transcendental do mundo fatual.0 conceito de transcendental utilizado por Deleuze não deve ser compreendido no sentido kantiano, em que uma estrutura cognitiva a priori permite formalizar a experiência possível, balizando os limites e possibilidades do uso da razão. De fato, Deleuze critica Kant por ter "decalcado as estruturas ditas transcendentais sobre os atos empíricos de uma consciência psicológica (...)" (Deleuze, 2006, p. 224), tornando as condições da experiência maiores do que a experiência condicionada, deixando escapar a singularidade sub-representativa do real e oferecendo, de antemão, uma imagem possível à experiência e ao pensamento.

Para o filósofo, "purgar o campo transcendental de toda a semelhança permanece a tarefa de uma filosofia que não quer cair nas armadilhas da consciência ou do cogito" (Deleuze, 2007, p. 149). A filosofia da diferença deve ser capaz de estabelecer, então, o que Deleuze chama de empirismo transcendental: o campo transcendental e o empírico devem ser perpassados por um plano aquém ou além da representação, capaz de dissolver a dicotomia entre sujeito e objeto, entre a estrutura cognitiva de um eu psicológico e os entes já individuados do mundo fenomênico. Tal campo transcendental sem sujeito terá como contrapartida, então, um mundo empírico sem objetos. A esfera da diferença interna e intensiva é desvelada como dimensão ontologicamente primeira em relação às diferenças externas

\footnotetext{
1 "Esse nível, o mais alto, é o que conhece a essência, designada por Platão com a palavra eîdos, a forma inteligível, a ideia, a verdade incondicionada." (Chauí, 2002, p. 253)
} 
e extensivas, entre os indivíduos já formados. Em A Lógica do sentido é a partir da elaboração da superfície do acontecimento imaterial que Deleuze buscará estabelecer para a linguagem tal campo diferencial sub-representativo.A esterilidade do sentido, ou acontecimento, interdita qualquer recurso a um sujeito psicológico ativo, capaz de organizar os dados da experiência conforme as exigências universais da razão, doando à natureza uma significação antropológica. É o que em Diferença e repetição (2006) Deleuze chama "síntese passiva": uma passividade ontológica primeira, respondendo pelas individuações singulares do mundo empírico, indiferente, portanto, aos gêneros e espécies representáveis. O sentido não é humano, portanto, pois responde pela autoafecção diferencial do ser, processo de dobra indiferente ao individual e ao coletivo, ao particular e ao geral, a "Deus, o mundo ou um eu" (Deleuze, 2007, p. 304). Contemplar, neste caso, não é participar das formas transcendentais, como em Platão, ou de um mundo já individuado e distribuído segundo gêneros primeiros, como em Aristóteles. E, no caso da teoria da linguagem contida em $A$ lógica do sentido, a função contemplativa responde pelo sentido como acontecimento impassível que, indiferente às ações e paixões realizadas no plano psicológico ou empírico, exprime nele mesmo a gênese transcendental da diferença.

Tal esterilidade do sentido não implica, entretanto, nenhuma resignação. Retomando a filosofia de Nietzsche, Deleuze fala de um paradoxal amor fati que se por um lado corresponde à incapacidade da consciência voluntarista em transformar o que quer que seja do estado empírico de coisas, exprime, em contrapartida, a potência ontológica da linguagem em esposar as transformações sub-representativas e seguir as diferenças e singularidades que povoam o campo transcendental sem sujeito. Trata-se, segundo Deleuze (2007),

(...) da maior impotência daquele que fala e da mais alta potência da linguagem. Minha impotência em dizer o sentido do que digo, em dizer ao mesmo tempo alguma coisa e seu sentido, mas também o pode infinito da linguagem em falar sobre as palavras. (p. 31)

O sentido imanente aos acontecimentos é capaz de seguir, "esposar" (ao contrário de refletir) a contemplação ontológica que o ser faz sobre si. É o processo que o autor denomina "imaculada concepção" ou "gênese estática": nada muda no plano empírico ou psicológico, no estado de coisas efetuado. Mas, subitamente, todos os signos e toda causalidade ativa ou passional mudam de sentido. Ou melhor: adquirem um sentido; mas sob a condição de expressar, além e aquém dos objetos designáveis ou da manifestação de um eu psicológico, o infinitivo de um puro devir imaterial. 0 sentido torna-se capaz de afirmar o factum em sua dimensão singular, a efetuação do acontecimento em um estado de corpos como processo da infinita diferenciação interna do ser. Para o autor, somente a "conquista" do acontecimento é capaz de subverter as tiranias e opressões da transcendência, da representação e dos significados últimos, afirmando, contra qualquer ação voluntarista de uma consciência psicológica, a necessidade do acaso e a diferença em si mesma.A linguagem que exprime o acontecimento será aquela dos verbos infinitivos. Em vez da proposição "A arvore é verde", na qual o sujeito e predicado articulam-se segundo o gênero e a espécie, conforme significados primeiros submetidos à lógica da não contradição, teríamos uma expressão como "arvorar-verdejar", cujo sentido não depende de sua participação em uma essência primeira, mas de um devir dos termos que é inseparável de um processo diferencial de individuação. Desta maneira, não teríamos mais sujeitos nem predicados na proposição, já que podemos articular, igualmente, a expressão "verdejar-arvorar", exprimindo o processo de produção ontológica no qual o campo transcendental sem sujeito se atualiza infinitamente em uma pletora de singularidades paraestáticas. A temporalidade do acontecimento expressa, portanto, fora do ser presente concebido como identidade transcendental ou empírica, o “(...) devir que se divide ao infinito em passado e em futuro, sempre se esquivando ao presente" (Deleuze, 2007, p. 6), furtando-se a sua própria identidade.

Para Deleuze, o essencial é conceber o sentido como um processo de diferenciação imanente do ser que seja, ao mesmo tempo, perfeitamente consistente e lógico. Para tratar o sentido como diferença interna, séries que ligam o heterogêneo ao heterogêneo, o filósofo rejeita qualquer recurso a um centro mediador que deveria fornecer identidade à "anarquia corada" (Deleuze, 2007) da proliferação linguística. Estruturando a língua de acordo com um fundamento primeiro contra o qual as diferenças seriam mediadas de acordo com sua participação 
na ideia, a necessidade de fundar seria característica da ortodoxia filosófica, submetida tanto ao senso comum das representações compartilhadas quanto ao bom senso que supõe, no homem, uma inclinação natural ao verdadeiro (Deleuze, 2006).Seja, por exemplo, o recurso a um ego transcendental em Kant, ou a contemplação das ideias primeiras em Platão, para Deleuze trata-se de perverter a dicotomia entre fundamento e afundamento, altura das ideias e profundidade dos corpos, o duplo impasse colocado pelo pressuposto representacional de que, fora da boa ordem do idêntico, teríamos o abismo das diferenças sem conceito, dos corpos sem linguagem e das palavras sem sentido, esta "noite indiferente em que todas as vacas são pretas" (Deleuze, 2006, p. 383). 0 duplo impasse é tematizado nas páginas de $A$ lógica do sentido através da pletora de dualidades que a linguagem que se propõe exprimir o devir deverá perverter: comer-falar, empírico-transcendental, objetos parciais-falo das alturas, etc.

A superfície de sentido tem a função, então, de devolver à linguagem "sua" capacidade interna de expressão, cortada qualquer referência a um estado empírico de coisas designáveis ou a um eu psicológico "significante". Se "o sentido como expresso não existe fora da expressão" (Deleuze, 2007, p. 41), a linguagem deve fazer dizer, em si mesma, o sentido, e dizê-lo conforme a univocidade de uma superfície onde o heterogêneo não se separa do heterogêneo, para ganhar consistência.

\section{Lacan e o inconsciente linguístico.}

Ora, na empreitada de A lógica do sentido, Deleuze utiliza a psicanálise e, mais profundamente, a de Lacan, como interlocutores essenciais na busca por pensar uma linguagem pós-representacional, fato que é justamente assinalado por Zizek² (2003). A elaboração da casa vazia, do ocupante sem lugar ou do lugar sem ocupante, dialoga explicitamente com a teoria lacaniana do inconsciente linguístico

\footnotetext{
2 “É (...) a razão pela qual Lacan apreciava tanto A lógica do sentido: a quase-causa deleuziana não é o equivalente do objeto pequeno a de Lacan, esta entidade pura, imaterial, espectral, que serve de objeto-causa do desejo?". (Zizek, 2003, p. 43)
}

e também com a função do objeto pequeno $a$, como objeto presente na sua própria ausência, furtando-se à dualidade empírico-transcendental por se deslocar continuamente ao longo das duas séries dicotômicas, garantindo a ressonância diferencial que impede o fechamento das séries em torno de um estado empírico de coisas ou de um ego transcendental. Trata-se de uma "instância paradoxal" que “(...) assegura, pois, a convergência das duas séries que percorre, com a condição, porém, de fazê-las divergir sem cessar" (Deleuze, 2007, p. 43).Segundo Klautau (2007), o objeto pequeno $a$, conceituado por Lacan em 1960, é o desdobramento de uma noção fundamental introduzida em seu seminário sobre a relação de objeto (1956-1957), aquela que postula a falta de objeto como central na constituição do desejo. Ele é o que emerge, então, de uma dupla impossibilidade, no "(...) recobrimento de duas faltas" (Lacan, 1964/1985, p. 207). Por um lado, a falta, no campo empírico, do objeto que satisfaria o desejo e responderia pela completude do sujeito; por outro, a impossibilidade da estrutura linguística em completar-se como instância transcendental significativa, fornecendo ao sujeito o sentido unívoco de sua linguagem e permitindo a relação comunicacional intersubjetiva. É necessária uma instância paradoxal, um núcleo irredutível à representação que, furtando-se a sua própria identidade, possa mediar cada termo da série linguística com sua própria dessemelhança, garantindo a articulação tanto entre a presença e a ausência do sentido na linguagem, quanto entre a presença e a ausência do objeto do desejo, no mundo.

Para Lacan, o sentido apenas se dá no a posteriori linguístico, ou seja, sempre descentrado em relação ao discurso coerente da consciência. $\mathrm{O}$ autor, buscando retornar à radicalidade da descoberta freudiana do inconsciente, afirma que este "(...) se situa neste ponto em que, entre a causa e o que ela afeta, há sempre claudicação (Lacan, 1985/19641965, p. 27). 0 descentramento do ego é fruto da determinação inconsciente do sujeito, subordinado a Outra lógica da qual apenas podemos recolher os efeitos de sentido. São as séries significantes que, por não terem em si mesmas quaisquer significado, não podem ter uma presença na linguagem, sendo aquilo mesmo que desestabiliza a consistência do discurso significativo: "O significante deve ser concebido em primeiro lugar como distinto da significação. 0 que o distingue é o fato de ser em si mesmo 
sem significação própria" (Lacan, 1985/1955-1956, p. 227).

O inconsciente linguístico, inferido como Outro lugar que desestabiliza a coerência do ego, possui uma lógica própria, que pode ser deduzida através da depuração dos efeitos de sentido gerados pela fala. Mas esta Outra lógica da estrutura linguística, se pode ser inferida a partir dos atos falhos, lapsos de linguagem e sintomas que interrompem, necessariamente, qualquer significação unívoca do sentido, nunca pode ser traduzida em uma presença significativa. De fato, se "uma vez introduzido no jogo dos símbolos, você é sempre forçado a se comportar segundo uma regra" (Lacan, 1985/19551956, p.63) que o determina, esta regra, sendo a da estrutura significante, não se articula segundo uma forma unitária, totalizada, significativa.

Como no caso do extrasser do acontecimento imaterial, em Deleuze, poderíamos falar, então, do extrasser da estrutura significante, das oposições binárias e puramente relacionais em que o inconsciente simbólico estrutura-se como uma linguagem. A dimensão simbólica não pode ser, portanto, imaginada ou percebida, como se perceberiam os objetos já indivíduos do mundo fenomenal: "Tentem imaginar, por consequência, o que seria a aparição de um puro significante. Naturalmente, nem mesmo podemos imaginá-lo, por definição" (Lacan, $1985 / 1955-1956$, p. 277). Sendo uma rede puramente diferencial de articulações de oposição, em que "um termo é tudo aquilo que ele não é" ${ }^{3}$, a forma de sua captação deve ser eminentemente simbólica, formal, diferencial, recusando os efeitos imaginários das significações estáveis que invariavelmente remetem ao eu consciente e à vontade psicológica. Na construção do conceito de inconsciente linguístico, Lacan (1998) parte da dicotomia saussuriana entre língua e fala, enunciação coletiva simbólica e enunciado individual, mas para subvertê-la. Afirma que a estrutura diferencial do signo linguístico, o dístico saussuriano significado/significante (conceito/imagem acústica), não se constitui como uma

\footnotetext{
3 Lacan utiliza-se, aqui, da teoria saussuriana do valor dos signos: "Quando se diz que os valores correspondem a conceitos, subentende-se que são puramente diferenciais, definidos não positivamente por seu conteúdo, mas negativamente por suas relações com os outros termos do sistema. Sua característica exata é ser o que os outros não são."( Saussure, 2006, p. 136)
}

cadeia fechada que os indivíduos empíricos, em seus atos de fala particulares, atualizariam de maneira mais ou menos imperfeita, conforme aos códigos linguísticos que compõem as comunidades humanas ${ }^{4}$. Pelo contrário, ao inverter a dicotomia saussuriana, e postular o significante como determinante do significado (significante/significado), Lacan advoga um descentramento essencial entre a estrutura significante simbólica e os efeitos de significado imaginários.

Daí segue que "o inconsciente é estruturado como uma linguagem" (Lacan, 1998): como. 0 efeito de metáfora do significante "como" na proposição afirma o perpétuo deslocamento do sentido, a irreparável fenda entre conteúdo manifesto e conteúdo latente, interditando o significante como aquele diz o sentido verdadeiro do significado. A metáfora e a metonímia tornam-se, então, operações fundadoras da linguagem e, portanto, do sujeito, ao estabelecer o deslizamento infinito do significado sob o significante.

Mas como, então, responder pela estabilidade da cadeira significante? De que maneira conceber, se qualquer recurso à imagem (Gestalt) e ao significado são interditados, a estabilidade de uma cadeia puramente binária, diferencial, relacional, impedindo que a proliferação do significante sob o significado não lance a língua e, portanto, o sujeito, no "mau infinito" de um deslocamento contínuo, de uma negação perpétua do sentido?

Lacan soluciona o problema da consistência da cadeia simbólica, por um lado, e dos efeitos reais de significação, por outro, postulando a ação de um terceiro. É o significante-mestre, S1, único significante da cadeia que não significa nada e que, por sua negatividade absoluta, interna, se intercede entre os termos da cadeia simbólica (S2, S3, Sn...), mediando o "conflito" da negação perpétua que um significante faz de todos os outros, na busca infinda por adquirir significado. Segundo Caldas,

(...) a linguagem comporta um buraco que a fala contorna e recobre, mas não obtura jamais. Desta fala emerge como cifra originária, o S1, significante mestre a fazer série com S2 e Sn, série que produz um sa-

\footnotetext{
4 De fato, Saussure define a língua como "social em sua essência e independente do indivíduo" (Saussure, 2006, p.27).
} 
ber eternamente renovável, contudo, inexoravelmente não todo (Caldas, 1993, p.137)

A lógica significante só adquire sustentação, na teoria lacaniana, quando a relacionamos à presença de uma ausência: o significante fálico, S1. É ele que sustentará a articulação diferencial como estrutura, cadeia (S2, S3, Sn...), e produzirá, à margem de sua ausência, os efeitos de sentido. Enunciado e enunciação, língua e fala, não mais se opõem como o transcendental e o empírico, o coletivo e o individual, como ainda era o caso na linguística saussuriana, mas se comunicam através desta instância radicalmente negativa que (como o objeto pequeno a em relação à dimensão fenomenal da experiência) impede que a estrutura transcendental se feche sobre si, gerando um código transindividual da língua. Segundo Zizek

A partir do momento em que lidamos com uma rede diferencial dos significantes, temos de inferir na rede de diferenças também a diferença entre o significante e sua ausência como uma oposição significante, ou seja, temos de considerar como parte do significante sua própria ausência: temos de postular a existência de um significante que é a própria falta do significante, o que coincide com o lugar da inscrição do significante (Zizek, 1991, p. 32)

Este significante, S1, ou significante mestre, é aquele que não significa nada, que não pode representar nenhum significado, mas que serve como termo mediador a todos os elementos da cadeia, confrontando-os com uma ausência fundamental que os impede de alcançar um sentido estável, definitivo. E o que descrevemos como objeto pequeno a é o correlato, para o mundo empírico dos objetos do desejo, desta operação de alienação, na qual o sujeito que emerge como determinado pela estrutura encontra sempre um resto, um elemento não simbolizável que, interior à própria estrutura, garante, entre ele e o Outro, a comunidade de uma falta comum (Lacan, 1985/1965-1966).

Trata-se da emergência do desejo, como desejo do desejo do Outro, e da dimensão barrada, ou ausente, do Outro enquanto estrutura totalizante. A estabilização das diferenças vem da incidência/ ausência do Um como direção impossível na qual, entretanto, as cadeias significantes se precipitam. Mas o impossível, neste caso, é tornado interior à própria cadeia; a abertura não é mais exterior, imaginária, como seria o caso se se supõe o falo completo que viria "resolver" a articulação diferencial da estrutura.

É esta impossibilidade no cerne do significante mestre que responde também pelo conceito de Real em Lacan, marcando a incidência de um núcleo irredutível ao Outro simbólico que é, entretanto, "interior" a sua estruturação. 0 Real é um além do nome, mas um além imanente ao próprio nome, "aquilo" que, sempre retornando, articula, na impossibilidade do sujeito em reparar a fenda de onde emerge a compulsão à repetição, passagem necessária pela presença/ausência interior à inscrição fálica.

Entre as muitas formulações do Real que Lacan oferece em sua obra, uma delas postula que ele constitui um resto que "não para de não se escrever" (Lacan, 2008/1972-1973, p. 101). A segunda negativa, "não para de não...", marca a necessidade do impossível, em vez da imaginarização de uma possível presença do falo, em que este poderia, no futuro, reparar sua incompletude, ou, ainda, de uma negação ainda exterior, onde o Real seria "somente" "aquilo que não se escreve". 0 impossível, através da negatividade interposta pelo $\mathrm{S} 1$ à cadeia significante e a si mesmo, torna-se o (não) lugar de inscrição interior ao próprio deslizamento do símbolo. Se o desejo é sempre deslocado em relação a sua meta, articulado em torno de uma impossibilidade e estruturado pela busca de um sentido irremediavelmente perdido, esta busca pode, entretanto, afirmar sua própria incompletude, forma ética de um sujeito não "ceder em seu desejo" (Lacan, 2008/1959-1960, p. 357).

Segundo a leitura feita por Zizek (1991) da filosofia hegeliana a partir do pensamento de Lacan, trata-se, na estrutura do símbolo, da mediação que o significante mestre impõe à cadeia de significantes em seu duplo aspecto de presença e ausência, da operação hegeliana da "negação da negação". Não, entretanto, como síntese positiva dos contrários e pacificação da contradição entre sentido e não sentido, mas enquanto afirmação da incompletude da linguagem e, portanto, da fenda aberta no sentido, de onde pode emergir um sujeito como desejante.

\section{Sobre linguagens e corpos: dizer o sentido, construir o desejo}

Podemos perceber como as considerações desenvolvidas a respeito do inconsciente linguístico 
lacaniano e da lógica do sentido deleuziana permitem-nos apontar uma comunidade entre o projeto dos dois autores. Deleuze parte de uma crítica à filosofia da representação para aportar, em $A$ lógica do sentido, na elaboração de uma teoria linguística pós-representativa, capaz de exprimir o devir como acontecimento imaterial. Já Lacan, em seu retorno a Freud e em sua retomada crítica de algumas das teses do "estruturalismo" saussuriano, elabora a impossibilidade da dimensão simbólica em fornecer, ao sujeito que ela determina, uma articulação adequada de seu desejo, um significado verdadeiro que respondesse a sua demanda por representação e sentido. Deleuze, no mesmo livro, utiliza então o que chama "paradoxo de Lacan" (Deleuze, 2007, p. 41), na busca por conceituar o não lugar de um termo que se furta a sua própria identidade, garantindo a articulação diferencial entre linguagem e sentido, por um lado, e o mundo empírico das ações e paixões entre os corpos, por outro.

Entretanto, há uma diferença importante, que gostaríamos de investigar, entre o pensamento lacaniano e o deleuziano. Diferença que se tornará acerba na obra de Deleuze posterior a $A$ lógica do sentido, $O$ anti-Édipo, revelando o que, para o filósofo, constitui uma ambiguidade fundamental no projeto de Lacan. É que, para Deleuze, é necessário surpreender o sentido na própria superfície linguística, sem ter como recurso a paradoxal negatividade constitutiva do inconsciente concebido por Lacan em seu retorno a Freud.

Em A lógica do sentido, o filósofo francês ainda não havia conceituado satisfatoriamente o que em $O$ anti-Édipo, escrito com Félix Guattari, nomeará Corpo sem Órgãos, conceito que se desdobrará, em Mil Platôs (1980) e O que é a filosofia? (2009), no plano de consistência ou de imanência. Trata-se da necessidade de pensar a paradoxal estabilidade do plano transcendental de diferenças puras, mas sem qualquer recurso à mediação do falo castrado. Um plano que não se subordine à identidade do "Eu, de Deus ou do mundo" (Deleuze, 2007, p. 304), certamente, mas que, diversamente do inconsciente psicanalítico, possa ser produzido, relacionado a uma paradoxal presença que não é aquela do sujeito ou do objeto, da significação ou da representação.

Para além de deduzir a estrutura através de seus efeitos desestabilizadores no discurso consciente, as formações do inconsciente trabalhadas por Lacan (Lacan, 1999/1957-1958): lapsos de linguagem, sintomas neuróticos, atos falhos e chistes, Deleuze buscará conferir plena positividade e consistência a um sentido que não mais se opõe, ainda que radicalmente, às significações da consciência. $O$ anti-Édipo elabora um conceito de inconsciente como produção ininterrupta de realidade, e não mais a dicção de uma estrutura que busca formalizar o Real. Tal inconsciente não poderá mais ser concebido, portanto, através da formulação do significante mestre, estruturalmente castrado, presidindo a mediação das articulações significantes.Trata-se de uma aposta deleuziana fundamental: é possível dizer o sentido, construir a superfície da qual o sentido emerge como acontecimento extratemporal, não subordinado, quer ao tempo cronológico e evolutivo das significações lineares, quer ao tempo ideal dos significados eternos. Mas quer, ainda, ao tempo sincrônico de uma matriz estrutural, em que a repetição é articulada em torno da impossibilidade de se simbolizar a "experiência" do Real, através do retorno de um resto não estruturável, dimensão traumática irredutível na constituição do sujeito.

Para a construção de tal plano de consistência, ou Corpo sem Órgãos, é necessário acompanhar a psicanálise em sua crítica ao referir o significado a um sujeito transcendental ou a um estado de coisas empírico. Mas é preciso também arriscar um passo além: recusar o recurso a um inconsciente simbólico, tematizando uma nova lógica da repetição para além da contradição irresolúvel entre linguagem e pulsão, sentido e não sentido. É a repetição pela qual Deleuze já clamava, quando na obra Diferença e repetição interpreta o eterno retorno de Nietzsche como repetição ontológica da diferença.

Ora, como argumenta José Gil (2007), o lugar que o Corpo sem Órgãos ocupa em A lógica do Sentido, testemunha a insuficiência, a esta altura do trajeto deleuziano, da construção desta superfície ao mesmo tempo consistente e puramente diferencial ${ }^{5}$. Ele aparece, em um primeiro momento, remetido à profundidade dos corpos, à pulsão desregrada para além de sua captura pela linguagem. $\mathrm{O} \mathrm{CsO}^{6}$ é, aqui,

\footnotetext{
5 "Tudo estava a postos, dir-se-ia, em Lógica do sentido, para que surgisse este novo regime de pensamento. (...) e, contudo, Lógica do sentido não traça um plano de imanência." (Gil, J., 2008, p. 167)

6 Passaremos, a partir de agora, a grafar o termo Corpo sem Órgãos como CsO.
} 
o índice de uma destruição. Palavras que têm materialidade de corpos perfuram a superfície de sentido e conduzem o pensamento ao abismo de um indiferenciação essencial, de onde se extrai a radicalidade de um não senso exasperador.

Este CsO se aproxima da foraclusão da mediação fálica, que é descrita por Lacan como constituindo a experiência do despedaçamento da superfície simbólica e da cisão da separação entre palavras e coisas, símbolo e realidade, na psicose. Sendo assim, o que é excluído (foracluído) no simbólico - a mediação do falo castrado como articuladora do deslizamento do sentido - retorna no Real: "Na relação do sujeito com o símbolo, há a possibilidade de uma Verwerfung [foraclusão] primitiva, ou seja, que alguma coisa não seja simbolizada, que vai se manifestar no real" (Lacan, 1988/1954-1955).

Daí a descrição que Deleuze faz dos ferimentos verbais, do corpo despedaçado pela materialidade da língua, das palavras-sopro e palavras-grito, que corroem a superfície metafísica do sentido, subordinando a estrutura simbólica a uma terrível física dos corpos e palavras despedaçados. Radicalmente excluída de qualquer miragem de unificação fálica, e, portanto, do plano simbólico, a palavra torna-se coisa, objeto fragmentado, agressão corporal que prolifera no desmoronamento dos efeitos de significação.Mas, já em $A$ lógica do sentido, o filósofo aponta para outro aspecto do $\mathrm{CsO}$, que se tornará fundamental em sua crítica posterior à psicanálise e para a elaboração de toda sua filosofia ulterior. Para além da não inscrição do significante mestre como mediador da multiplicidade da cadeia significante, existe a possibilidade de se pensar um CsO que possa se furtar ao falo castrado, ou ao "objeto evanescente das alturas" (Deleuze, 2007), sem constituir-se, entretanto, como fragmentação do sentido. É o corpo pleno, corpo glorioso das intensidades absolutas, que adquire outra consistência, diferente da representação bem fundada perseguida pela filosofia clássica ou do símbolo estrutural lacaniano. E, para sua construção, a mediação do falo, em sua função de introduzir Outra cena a toda significação imaginariamente estável, deverá ser recusada. De forma que, em $O$ anti-Édipo, Deleuze e Guattari poderão dizer a respeito do signo:

Se há uma escrita (...), é uma escrita no próprio Real, estranhamente plurívoca, nunca biunivocizada, linearizada, uma escrita transcursiva e nunca discursiva: é todo o domínio da inorganização real das sínteses passivas, no qual em vão buscaríamos algo que se pudesse chamar o Significante, e que não para de compor e decompor sua cadeia em signos que não têm vocação alguma para serem significantes.(Deleuze \& Guattari, 2010, p. 59)

A mediação fálica e a castração simbólica, de operações essenciais na estruturação do sujeito, passam a ser caracterizadas como mecanismos de captura do desejo, através da edipianização do inconsciente ligada a práticas sócio-históricas de repressão da realidade imanente das "máquinas desejantes":

"Como operação prática sobre o inconsciente, a castração é obtida quando os mil cortes-fluxos das máquinas desejantes, todos positivos, todos produtores, são projetados sobre um mesmo lugar mítico, isto é, o traço unitário do significante" (Deleuze \& Guattari, 2010, p. 86).

E o CsO, de termo que dramatizava o afundamento do sentido na experiência esquizofrênica, a foraclusão do falo castrado e a frágil tentativa de se recompor um corpo pleno, torna-se conceito capaz de responder pela superfície imanente e positiva da produção desejante. Se "produzir desejo é a única vocação do signo, em qualquer sentido em que isto se maquina" (Deleuze \& Guattari, 2010, p. 59), é o próprio sentido do conceito de desejo que muda de figura: "As relações lógicas dos conceitos da Lógica do sentido encarnam-se agora em movimentos reais do desejo; e isto muda tudo" (Gil, J., 2008, p. 168).

A lógica da estrutura significante é explicitamente recusada, em nome de outra concepção de linguagem que possa responder, igualmente, por um novo conceito de desejo e de inconsciente. Os autores põem-se a construir uma concepção pós-significante da linguagem e do sentido, e, portanto, da própria subjetividade. Agora não é apenas o sentido, como acontecimento imaterial, que revela a dimensão transcendental da diferença, mas a própria materialidade do real:

Como produzir e pensar fragmentos que tenham entre si relações de diferença enquanto tal, que tenham como relação entre si sua própria diferença, sem referência a uma totalidade original ainda que perdi$d a$, nem a uma totalidade resultante ainda que por vir?(...) A produção desejante é multiplicidade pura, 
isto é, afirmação irredutível à unidade. Estamos na idade dos objetos parciais, dos tijolos e dos restos [itálicos nossos](Deleuze \& Guattari, 2010, p. 62)

Para Deleuze e Guattari, se nossa idade é aquela dos objetos parciais, dos tijolos e dos restos, ela é contemporânea somente na medida em que se furta a seu próprio historicismo e atinge as condições de uma história universal que não é aquela das evoluções teleológicas ou do desdobramento de um sentido primeiro. Mas, também, que não é aquela do significante mestre, a negatividade radical que preside ao processo de inscrição simbólica de "um sujeito".

Trata-se da possibilidade de se pensar a diferença sem qualquer mediação. Deleuze e Guattari reivindicam a consistência das intensidades primeiras, do campo transcendental sem sujeito, ontologicamente anterior à estruturação significante da pulsão. Campo, portanto, indiferente à divisão binária entre natureza e cultura, onde a própria natureza e, nela, o "homem", são convocados dentro de uma mesma "universal produção primária" (Deleuze \& Guattari, 2010, p. 16). Não é o sujeito que emerge como desejante a partir da castração simbólica, mas a própria natureza que "se complica", em um processo de diferenciação infinita chamado desejo.

0 Real não é mais, portanto, aquilo que faz exceção ao jogo estruturado do significante e do significado, mas o que se apresenta imediatamente: "Se o desejo produz, ele produz real. Se o desejo é produtor, ele só pode sê-lo na realidade, e de realidade" (Deleuze \& Guattari, 2010, p. 43). De uma lógica da contradição, em que Real e símbolo engendram-se mutualmente sem qualquer possibilidade de resolução do conflito, de síntese, passamos a uma lógica do paradoxo, na qual é o real em si mesmo que se divide infinitamente, adquirindo consistência sem qualquer recurso ao símbolo ou à representação.

A desestabilização da estrutura linguística não remete mais, portanto, à função do Real conforme esta é concebida por Lacan, que a pensa negativamente, como limite interior ao símbolo, ausência de inscrição, castração fálica: "Falo do real como impossível na medida em que creio justamente que o real - enfim, creio, se este é meio sintoma, digam-me - é sem lei. 0 verdadeiro real implica a ausência de lei" (Lacan, 2007/1975-1976, p.133). Em Deleuze e Guattari, pelo contrário, é a "instabilidade" do real que ganha consistência, passando a responder pela própria produção desejante, já que "as máquinas desejantes só funcionam desarranjadas, desarranjando-se continuamente" ${ }^{\prime 7}$ (Deleuze \& Guattari, 2010, p.20).

Trata-se de um signo que não é mais significante, para um sujeito que não é mais alienado ao Outro simbólico. E, também, da consistência de uma topologia desejante não mais estruturada em torno de uma impossibilidade e de uma falta fundamental, mas que se apresenta, imediatamente, como síntese do heterogêneo, irredutível aos processos de efetuação de uma realidade empírica ou psicológica.

\section{Conclusão: o filósofo e o psicanalista.}

Em suas notas inseridas ao final do seminário 23, Jacques Alain Miller aproxima a teoria do Real e sua relação com o corpo, desenvolvida por Lacan no último período de seu ensino, ao conceito de $\mathrm{CsO}$ de Deleuze e Guattari. Para Miller,

Trata-se [em Lacan] de dizer, simplesmente, que o corpo existe como saco de pele, vazio, fora e ao lado de seus órgãos. Acabo de dizer a palavra que permite captar do que se trata: fundar o lugar exato onde é conveniente inscrever a elucubração, central em $O$ anti-Édipo, de um "corpo sem órgãos". 0 corpo sem órgãos é o corpo-saco. Sua ex-sistência aos elementos que ele contém, sua consistência de continente é a do conjunto vazio. (Lacan, 2007/1975-1976, p. 213-214)

Será, realmente, como coloca Miller, que podemos superpor o conceito de $\mathrm{CsO}$, conforme ele é pensado por Deleuze e Guattari, ao "corpo-saco" lacaniano, e à necessidade, central em sua teoria, de se contar a inscrição do falo castrado como indissociável à transformação dos significantes em cadeia, conjunto? Ou seja, de se inscrever a negatividade, como tal, na parturição da própria linguagem como estrutura? Reformulando a pergunta, em sentido inverso: será o CsO deleuziano um "nada" que se conta ao lado das séries do sentido, conferindo-lhes uma "não toda" estabilidade?

\footnotetext{
7 Trata-se de um enunciado que Deleuze e Guattari irão retomar, à época da elaboração de Mil Platôs, afirmando que "uma sociedade não se define por suas contradições, mas por suas linhas de fuga” (Deleuze, 1990, p. 212)
} 
Parece-nos que as coisas não se passam desta maneira. A característica de extrasser do CsO é indissociável de uma apresentação radicalmente positiva, isto é, o CsO, ao contrário do Real como sem lei, ou vazio de lei, possui uma "lei". Mas o que é, então, possuir lei, para o caso de uma instância que tem, justamente, a função de abolir todas as leis da representação e da significação? É como Deleuze já apontava em A lógica do sentido, a lei de um jogo ideal, jogo capaz de, antes de suspender as conexões realizadas segundo os códigos da representação ou da significação, afirmar, a cada lance singular, a necessidade do acaso:

1) Não a regras preexistentes, cada lance inventa suas regras, carrega consigo suas próprias regras. 2) Longe de dividir o acaso em um número de jogadas realmente distintas, o conjunto das jogadas afirma todo o acaso e não cessa de ramificá-lo em cada jogada. 3) As jogadas (...) são as formas qualitativas de um só e mesmo lance, ontologicamente uno (...) 4) Um tal jogo sem regras, sem vencedores nem vencidos, (...) em que a destreza e o acaso não mais se distinguem, parece não ter qualquer realidade (...) mas, precisamente: ele é a realidade do pensamento puro. (Deleuze, 2007, p. 62-63)

Pensamento puro, certamente. Mas, como vimos, a partir de $O$ anti-Édipo, ele será, também, ação e desejo puros: "tudo muda quando o pensamento, deixando de ser pensamento da vida, se torna ele próprio vida" (Gil, 2008, p. 167). Para tal jogo do sentido, do CsO e do plano de consistência, é necessária a operação pela qual ele possa ser pensado $e$ construído como ontologicamente primeiro em relação aos encadeamentos significantes ou significados. Ou seja, não como exceção interior ao plano da representação, núcleo inassimilável, mas como lance de dados ontológico imediato, o ser-aí da diferença nela mesma, sem qualquer mediação.

Vemos, então, que a construção de tal superfície para que o sentido possa se dizer, e de um plano de consistência, ou CsO, para que o desejo possa "se desejar", é essencial ao projeto filosófico de Deleuze. E ela marca, de acordo com o que procuramos demonstrar, uma diferença fundamental entre o pensamento do filósofo francês e o de Jacques Lacan.

Se ambos os autores convergem na crítica da representação e da consciência, parecem divergir quanto ao caráter assumido por esta crítica. Esta divergência, como vimos, aporta sobre a insistência deleuziana na necessidade de se dizer o sentido, ou de se "articular" o desejo. A nomeação, neste plano paradoxal de imanência, não mais indica qualquer tentativa de captura simbólica do Real, mas a produtividade mesma do desejo e da linguagem. Nesta nova articulação é recusado o recurso à concepção estrutural do inconsciente, em que haveria, presidindo as cadeias significantes, um significante mestre capaz de introduzir, no sujeito que ele representa, uma negatividade radical, incontornável. 0 inconsciente, dispensando qualquer mediação, se apresenta para Deleuze e Guattari subvertendo a contradição entre sentido e não sentido, entre Real e símbolo, através da consistência da diferença produtiva, genética.

Procuramos desenvolver, prioritariamente, as consequências que a diferença entre ambas as teorias tem para o pensamento da linguagem. Mas, em nosso trajeto, pudemos perceber como, embora possuindo a característica comum de uma crítica da representação, trata-se de duas formas distintas de se pensar o inconsciente e o desejo e, portanto, a própria subjetividade. Tal diferença, que se aprofunda a partir de $O$ anti-Édipo, acompanhará o desenvolvimento de toda a filosofia ulterior de Deleuze, trazendo consequências teóricas, éticas e políticas cujos contornos apenas pudemos indicar nos limites deste estudo.

\section{Referências}

Caldas, H. (1993). A subversão de Lacan. In A. Quinet (Org.). Jacques Lacan, a psicanálise e suas conexões. Rio de Janeiro: Editora Imago.

Chauí, M. (2002). Introdução à história da filosofia. Dos pré-socráticos a Aristóteles. São Paulo: Companhia das letras.

Deleuze, G. (2006). Diferença e repetição. Rio de janeiro: Graal.

Deleuze, G. (2007). A lógica do sentido. São Paulo: Perspectiva.

Deleuze, G. (1992). Conversações. Rio de Janeiro: Editora 34.

Deleuze, G., \& Guattari, F. (2010). O anti-Édipo- capitalismo e esquizofrenia. Rio de janeiro: Editora 34. 
Deleuze, G., \& Guattari, F. (1996). Mil Platôs (Vol. 3). São Paulo, Editora 34.

Deleuze, G., \& Guattari, F. (2009). O que é a filosofia? Rio de Janeiro: Editora 34.

Gil, J. (2008). A lógica do excesso. Lisboa: Relógio D’Água Editores.

Klautau, P. (2007). Winnicott e Lacan: a importância do conceito de objeto transicional na formulação do objeto $a$. In B. B. Jr. e F. Ortega (Org.), Winnicott e seus interlocutores. Ediouro Publicações: Rio de Janeiro.

Lacan, J. (1998). A instância da letra no inconsciente ou a razão desde Freud. In Escritos. Rio de Janeiro: Jorge Zahar.

Lacan, J. (1985). O Seminário, livro 3: as Psicoses. Rio de Janeiro: Jorge Zahar Editor.
Lacan, J. (1999.). O seminário, livro 5: as formações do inconsciente. Rio de Janeiro: Jorge Zahar Editor. Lacan, J. (2008). O seminário livro 7: a ética da psicanálise. Rio de Janeiro: Jorge Zahar Editor.Lacan, J. (1985). O seminário livro 11: Os quatro conceitos fundamentais da psicanalise. Rio de Janeiro: Jorge Zahar Editor.

Lacan, J. (1985). O seminário, livro 20: mais, ainda... Rio de Janeiro: Jorge Zahar Editor.

Lacan, J. (2007). O Seminário, livro 23: o sinthoma. Rio de Janeiro: Jorge Zahar Editor.Saussure, F. (2006). Curso de linguística geral. São Paulo: Editora Cultrix.

Zizek, S. (1991). O mais sublime dos histéricos - Hegel com Lacan. Rio de Janeiro: Jorge Zahar Editor.

Zizek, S. (2003). Organes sans corps - Deleuze et Conséquences. Éditions Amsterdam: Paris. 